\title{
Numerical Simulation of Deep Foundation Pit Construction under Complex Site Conditions
}

\author{
Huifen Liu $\left(\mathbb{D},{ }^{1}\right.$ Kezeng Li $\left(\mathbb{D},{ }^{2}\right.$ Jianqiang Wang, ${ }^{3}$ and Chunxiang Cheng ${ }^{1}$ \\ ${ }^{1}$ School of Transportation, Civil Engineering and Architecture, Foshan University, Foshan, Guangdong 528000, China \\ ${ }^{2}$ Hunan Technical College of Railway High Speed, Hengyang 421001, China \\ ${ }^{3}$ Shenzhen Cheng'An Internet of Things Technology Co., Ltd., Shenzhen 421002, China \\ Correspondence should be addressed to Kezeng Li; 767719631@qq.com
}

Received 18 December 2020; Revised 8 January 2021; Accepted 21 January 2021; Published 4 February 2021

Academic Editor: bingxiang yuan

Copyright (C) 2021 Huifen Liu et al. This is an open access article distributed under the Creative Commons Attribution License, which permits unrestricted use, distribution, and reproduction in any medium, provided the original work is properly cited.

Based on the deep foundation pit project of Laoguancun station of Wuhan rail transit line 16 and according to the engineering characteristics of the construction conditions and the site surrounding the environment, the method of combining field monitoring and finite element numerical simulation is adopted to analyze the law of stress and deformation of the deep foundation pit during excavation and support construction; it includes the horizontal displacement of the underground diaphragm wall, supporting axial force, and the ground surface settlement, which can be compared with measured data. Finally, some suggestions for monitoring and construction of the deep foundation pit in the subway station have been put forward and have certain reference value and practical guiding significance for the design and construction of similar engineering projects. The deformation monitoring of the retaining structure at the middle of the long side of the foundation pit should be strengthened during the construction process.

\section{Introduction}

In order to alleviate the traffic pressure on the ground in time in the process of urbanization, the construction of urban rail transit in China has been developed rapidly in recent years. The impact of the deep foundation pits for new subway stations under the complex conditions of site construction on the mechanical properties of the construction process also has higher requirements [1-5]. In the vicinity of existing subway stations, the construction of a new subway station is a complex work and system project with great construction risk. It is not only needed to avoid the impact of the new station on the existing station and its affiliated projects to the greatest extent but also necessary to reasonably evaluate and minimize the impact of existing subway stations that are very close (e.g., the distance between stations is about $10 \mathrm{~m}$ ) on the mechanical properties of the deep foundation pit of the newly built station during the excavation and support construction. Therefore, it is necessary to carry out targeted research to ensure the safety and stability of the new subway station during the construction process.

Numerical simulation is an important method to study the mechanical characteristics of the deep foundation pit construction process. Aiming at solving realistic foundation pit stability problems, Lambe once pointed out that the use of engineering experience or numerical analysis can more effectively solve such problems [6, 7]. The engineering experience method is highly subjective and has certain deficiencies on the theoretical basis, and it cannot accurately reflect the mechanical effects of deep foundation pits in the complex construction environment during the construction process. The problem to be solved is studied by numerical simulation in which analysis and prediction are more convenient and accurate [8-10]. Li et al. [11] carried out a three-dimensional numerical simulation of the construction process of a large-scale near-railway foundation pit by considering the actual construction sequence of excavation by layering and block-by-block excavation of the actual foundation pit, the interaction between the construction of 
the deep foundation pit and the adjacent railway load was studied and analyzed, and the deformation characteristics of the deep foundation pit adjacent to the railway during the excavation process were revealed. Yang et al. [12] used the self-developed analysis software F-RFPA2D to conduct a numerical simulation analysis of the Haizhu Square surface subsidence accident caused by the construction of the Guangzhou Metro line 2 tunnel and summarized the cause of the subsidence accident; Wang et al. [13] conducted a numerical simulation analysis on the confined aquifer at the Yishan Road Metro Station of Shanghai Metro line 9 and proposed several comparison options that can effectively control the settlement and deformation of the surrounding ground; Zhou et al. [14] used the Hangzhong Road subway station of Shanghai Metro line 10 as the research background and used the three-dimensional finite difference method to analyze the dewatering of foundation pits at different depths of the space enclosing structure, which optimizes the design of the foundation pit space enclosing structure. More relevant works can be found in, e.g., [15-17].

In this paper, relying on the deep foundation pit project of a subway transfer station in Wuhan, a three-dimensional finite element numerical model is established, and combined with field measured data, the force and deformation characteristics of the deep foundation pit station during the construction process under adjacent existing subway are analyzed, some useful conclusions are obtained.

\section{Project Basics}

Laoguancun station of Wuhan rail transit line 16 is parallel to the existing Laoguancun station of line 6 , as shown in Figure 1; the main body of the station adopts direct excavation-shoring construction method. The transfer station is an underground two-story island station, the floor depth at the center mileage of the effective platform is $16.68 \mathrm{~m}$, and the top of the station is covered with soil $3.2 \mathrm{~m}$; the main structure of the station has a total length of $227.3 \mathrm{~m}$ and a total width of $22.2 \mathrm{~m}$ (standard section); effective platform length is $140 \mathrm{~m}$, and the platform is $13 \mathrm{~m}$ wide, and it is a double-column three-span structure. The main enclosure structure adopts the combined support form of the underground diaphragm wall and internal support: the thickness of the underground diaphragm wall at the side adjacent to the existing station and the end of the large mileage is $1000 \mathrm{~mm}$, the thickness of the other underground diaphragm wall of the remaining side enclosure structure is $800 \mathrm{~mm}$, and a crown beam is set on the top of the wall. Reinforced concrete supports (first and second lanes) and steel supports (third and fourth lanes) are used as horizontal support systems.

\section{Establishment of the Numerical Model}

In order to comprehensively study the force and deformation characteristics of the retaining structure of the deep foundation pit of the newly built subway station during the excavation and support construction process, this paper combines the project design and construction plan to establish a three-dimensional finite element numerical model for calculation and analysis.

3.1. Basic Assumptions of the Numerical Model. The deep foundation pit of this subway station is a long strip, which is close to the existing subway station. The construction environment of the construction site is changeable when the foundation pit is excavated in sections. There is a lack of detailed reports related to the site soil reinforcement test and the main structure of the existing station. In order to make the built model close to reality and not be complicated, thereby affecting the efficiency of finite element analysis and calculation, certain simplifications and assumptions are made on modeling and analysis calculation. The specific assumptions are as follows:

(1) The interface of each soil layer of the site is kept level, and the average thickness of each soil layer is taken

(2) Excluding the influence of some interlayer soil, the soil quality is uniform in the same depth range, and the spatial unevenness of the actual soil layer is not considered

(3) Assume that, before each soil excavation construction, groundwater has fallen to at least $2 \mathrm{~m}$ below the soil excavation surface, and the underground diaphragm wall has a good water stopping effect, so the influence of groundwater on the site during the excavation of the foundation pit is not considered

(4) Regardless of the stress distribution and deformation of the soil in the site before foundation pit excavation, the value can be obtained by referring to the geological survey report

(5) For the construction process of the foundation pit, set up numerical simulation working conditions based on one-time excavation layer by layer, without considering the impact of segmentation and partition excavation on the foundation pit during the actual construction process

(6) The physical and mechanical properties of the underground diaphragm wall remain unchanged along the depth of the wall, and the frictional contact coefficient with the surrounding soil layers is not affected by the depth

(7) Regardless of the specific distribution of construction machinery, building materials, and muck around the foundation pit, they are uniformly arranged along the $20 \mathrm{~m}$ range around the edge of the foundation pit according to the ground overload of $20 \mathrm{kPa}$

3.2. Three-Dimensional Numerical Model. According to research findings and actual engineering experience, during the excavation and support construction of a foundation pit the depth of its impact on the surrounding site is generally 2 to 4 times the depth of the excavation of the foundation pit, and the width of the impact is 3 to 5 times that of the excavation depth. The size of the overall comprehensive 
model given in this paper is $450 \mathrm{~m} \times 168 \mathrm{~m} \times 52 \mathrm{~m}$, as shown in Figure 2.

In this paper, the modified Mohr-Coulomb constitutive model is used in the calculation model to simulate the engineering characteristics of the soil during the excavation process of the foundation pit. Considering that the reinforcement of the soil layer at the bottom of the foundation pit and between the stations will strengthen the supporting capacity of the retaining system, referring to the deep foundation pit engineering experience in Wuhan area and the geotechnical survey report of this project, the physical and mechanical parameters of each layer of the site are appropriately improved. The thickness of each soil layer and the main physical and mechanical properties of the simplified site are shown in Table 1. The constitutive parameters of the deep foundation pit retaining structure system of the newly built station and the main structural slabs and columns of the existing station in the model are shown in Tables 2 and 3, respectively.

3.3. Simulation of Construction Conditions. According to the construction plan of this project, the soil excavation surface in the foundation pit is located at a certain depth below the internal support axis to be erected every time $(0.5 \mathrm{~m}$ below the concrete support axis and $0.4 \mathrm{~m}$ below the steel support axis). The main simulated construction conditions are shown in Table 4.

\section{Results of Numerical Simulation}

It is stipulated that the $X$-axis direction is the length direction of the foundation pit, and the $Y$-axis direction is the width direction of the foundation pit, both of which are horizontal; the depth direction of the foundation pit is the $Z$ axis direction, and the vertical direction is positive.

\subsection{Horizontal Displacement of the Underground Diaphragm} Wall. Figures 3 and 4 show the horizontal displacement cloud diagrams of the underground diaphragm wall in the $Y$ and $X$-direction under various analysis conditions, respectively. It is easy to see from them that the deformation gradually develops into the foundation pit during the excavation process of the foundation pit; the maximum horizontal displacement of the underground diaphragm wall on each side of the foundation pit appears in the middle of the side, and as the foundation pit goes deeper, the excavation process gradually moves downward along the wall; the deformation of the underground diaphragm wall on the long side of the foundation pit is more obvious than that of the underground diaphragm wall on the underground short side of the foundation pit. Finally, the maximum deformation on the long side of the foundation pit is close to twice the maximum deformation on the short side. Figure 5 shows the extracted horizontal displacement simulation curve of the underground diaphragm wall at different positions of the foundation pit under various calculation conditions. It can be seen from Figure 5 that when the foundation pit is excavated to the bottom of the pit, the maximum horizontal displacement of the wall in the middle section of the long side on the east side of the foundation pit is about $38 \mathrm{~mm}$, and the maximum horizontal displacement of the wall in the middle section of the short side of the north side of the foundation pit is about $20 \mathrm{~mm}$. Near the section on the east side of the north end of the foundation pit, the maximum horizontal displacement of the wall is about $25 \mathrm{~mm}$, and the maximum horizontal displacement of the wall at each of the above positions appears at the depth of $2 / 3$ of the wall height below the top of the wall.

The above analysis results show that the underground diaphragm wall in the middle of the north short side of the foundation pit has the smallest deformation, and it is next located near the east end of the north end of the foundation pit, and the underground diaphragm wall in the middle of the long side of the foundation pit has the largest deformation, which should be the key area for monitoring the deformation of the enclosure structure during the excavation of the deep foundation pit.

4.2. Internal Support Axial Force. According to the calculation results extracted by numerical simulation, the standard section of the foundation pit and the sections on the east side of the north end of the foundation pit are selected to analyze the changes in the axial force of each support with the progress of the working conditions. The statistics are shown in Table 5.

From the data in Table 5, it can be found that, with the progress of the construction conditions, the axial force of the first support at different positions of the foundation pit plane has decreased. When the foundation pit is excavated to the base, the axial force of the horizontal straight brace of the standard section and the horizontal diagonal brace at the north end is very close, about $100 \mathrm{kN}$, and the first axial force of the first support at different positions of the foundation pit under all conditions. It is horizontal straight brace at the standard section $>$ horizontal diagonal brace at the north end $>$ horizontal straight brace at the north end, indicating that the space effect at the end of the foundation pit is more obvious, which is beneficial to the stress of the first support; the axial force of the second and third supports at each position of the foundation pit plane fluctuates up and down with the progress of the working conditions and eventually stabilizes; the last excavation of the soil in the foundation pit causes the axial force of the fourth support to significantly increase. On the whole, it can be found that the axial force of the upper support decreases after the setting of the second and the fourth support. For example, at the standard section of the foundation pit, the axial force of the first horizontal brace decreased from $-182.32 \mathrm{kN}$ to $-155.12 \mathrm{kN}$; the axial force of the third horizontal brace decreased from $-932.17 \mathrm{kN}$ to $-732.17 \mathrm{kN}$. During the entire excavation process of the foundation pit, the axial force of the second support is the largest. When the foundation pit is excavated to the bottom of the pit, the maximum value has reached $-2413.22 \mathrm{kN}$. Therefore, during the construction process, 


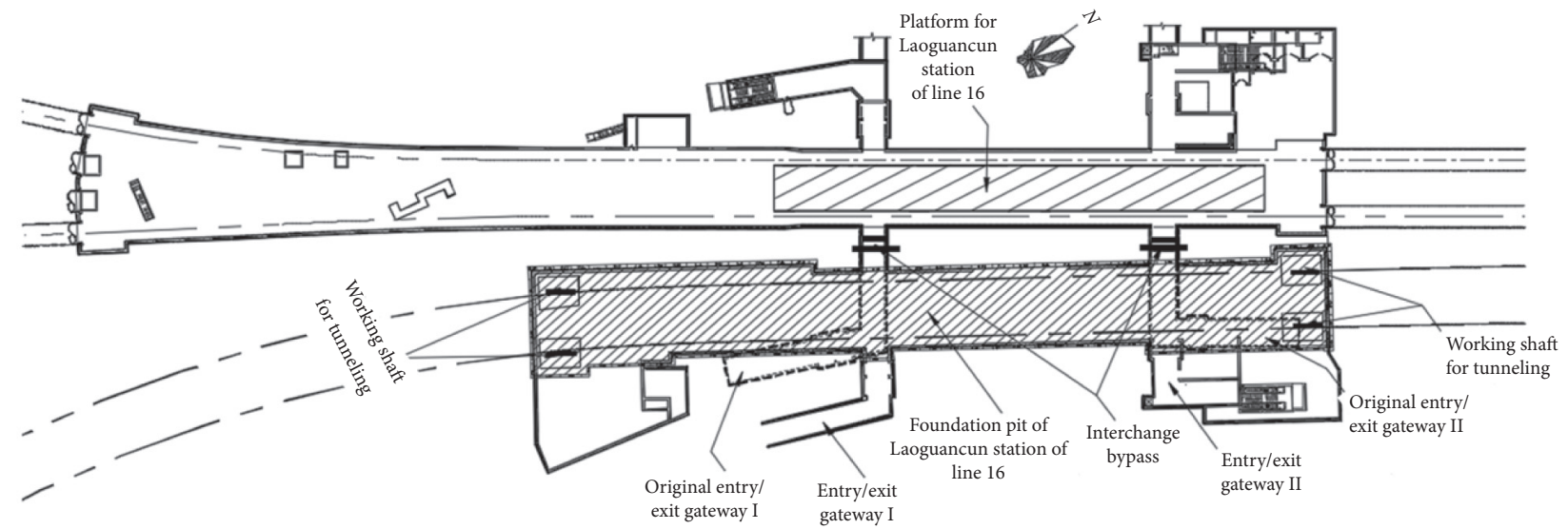

FigURE 1: Schematic project layouts.
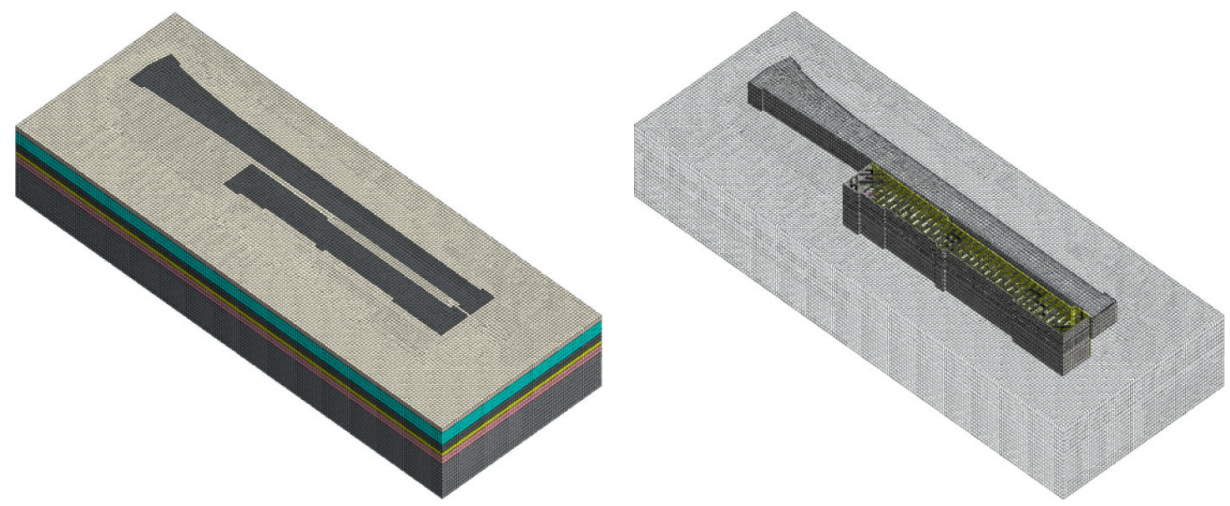

FIGURE 2: Numerical simulation model.

TABLE 1: Main physical and mechanical parameters of the soil layer.

\begin{tabular}{|c|c|c|c|c|c|c|c|c|}
\hline Soil/rock & Soil thickness (m) & $\begin{array}{l}\text { Soil weight } \\
\left(\mathrm{kN} / \mathrm{m}^{3}\right)\end{array}$ & Cohesion $(\mathrm{kPa})$ & Friction angle $\left({ }^{\circ}\right)$ & $\begin{array}{c}E_{50} \\
(\mathrm{kN} / \\
\left.\mathrm{m}^{2}\right) \\
\end{array}$ & $\begin{array}{c}\mathrm{E}_{0 \mathrm{ed}} \\
(\mathrm{kN} / \\
\left.\mathrm{m}^{2}\right) \\
\end{array}$ & $\begin{array}{c}E_{\mathrm{ur}} \\
(\mathrm{kN} / \\
\left.\mathrm{m}^{2}\right)\end{array}$ & Poisson's ratio \\
\hline (1-2) plain fill & 3.69 & 18.5 & 15 & 10 & 3600 & 3600 & 10800 & 0.30 \\
\hline (3-1) clay & 8.73 & 17.9 & 20 & 12 & 5500 & 5500 & 17000 & 0.31 \\
\hline (3-4) mucky silty clay & 5.52 & 17.6 & 15 & 10 & 3500 & 3500 & 10200 & 0.35 \\
\hline (7-2a) silty clay & 3.24 & 19.8 & 30 & 15 & 9500 & 9500 & 32000 & 0.30 \\
\hline (7-3) silty clay & 5.70 & 19.8 & 25 & 13 & 7500 & 7500 & 28000 & 0.32 \\
\hline (9) clay gravel, pebbles & 25.12 & 21.1 & 50 & 20 & 15000 & 15000 & 50000 & 0.28 \\
\hline
\end{tabular}

TABle 2: Constitutive parameter of the supporting structure.

\begin{tabular}{lcccc}
\hline Structure type & Elastic modulus $(\mathrm{MPa})$ & Poisson's ratio & Weight $\left(\mathrm{kN} / \mathrm{m}^{3}\right)$ & Note \\
\hline Underground diaphragm wall & $3.0 \times 10^{4}$ & 0.2 & 24 & $2 \mathrm{D}$ linear elastic model \\
Purlin & $3.2 \times 10^{4}$ & 0.2 & 24 & 1D linear elastic model \\
Concrete support & $3.2 \times 10^{4}$ & 0.23 & 24 & 1D linear elastic model \\
Steel support & $2.3 \times 10^{5}$ & 0.25 & 20 & 1D linear elastic model \\
\hline
\end{tabular}

TABle 3: Constitutive parameter of the main structure in the existing station.

\begin{tabular}{lcccc}
\hline Structure type & Elastic modulus $(\mathrm{MPa})$ & Poisson's ratio & Weight $\left(\mathrm{kN} / \mathrm{m}^{3}\right)$ & Note \\
\hline Underground diaphragm wall & $3.0 \times 10^{4}$ & 0.2 & 24 & $2 \mathrm{D}$ linear elastic model \\
Station floor & $3.25 \times 10^{4}$ & 0.2 & 24 & 2D linear elastic model \\
Station pillar & $3.5 \times 10^{4}$ & 0.2 & 24 & 1D linear elastic model \\
\hline
\end{tabular}


TABLE 4: Simulated construction condition of deep foundation pit excavation.

Construction

condition

Scenario 1

Scenario 2

Scenario 3

Scenario 4

Scenario 5

Scenario 6

Scenario 7
Scene description

Initial ground stress balance (settling to zero)

Construct an underground diaphragm wall

The soil of the foundation pit is excavated to a depth of $-1.5 \mathrm{~m}$ below the surface; in addition, a crown beam and a concrete support are arranged at the position of $-1 \mathrm{~m}$

The soil of the foundation pit is excavated to a depth of $-7.5 \mathrm{~m}$ below the surface; in addition, the ring beam and the second concrete support are set at the position of $-7 \mathrm{~m}$

The soil of the foundation pit is excavated to a depth of $-10.22 \mathrm{~m}$ below the surface; in addition, a steel purlin and a third internal support (steel support) are set at $-9.82 \mathrm{~m}$

The soil of the foundation pit is excavated to a depth of $-14.2 \mathrm{~m}$ below the ground surface; in addition, a steel purlin and a fourth internal support (steel support) are set at a position of $-13.8 \mathrm{~m}$ Excavation of the foundation pit soil to the elevation of pit bottom $(-17.94 \mathrm{~m})$

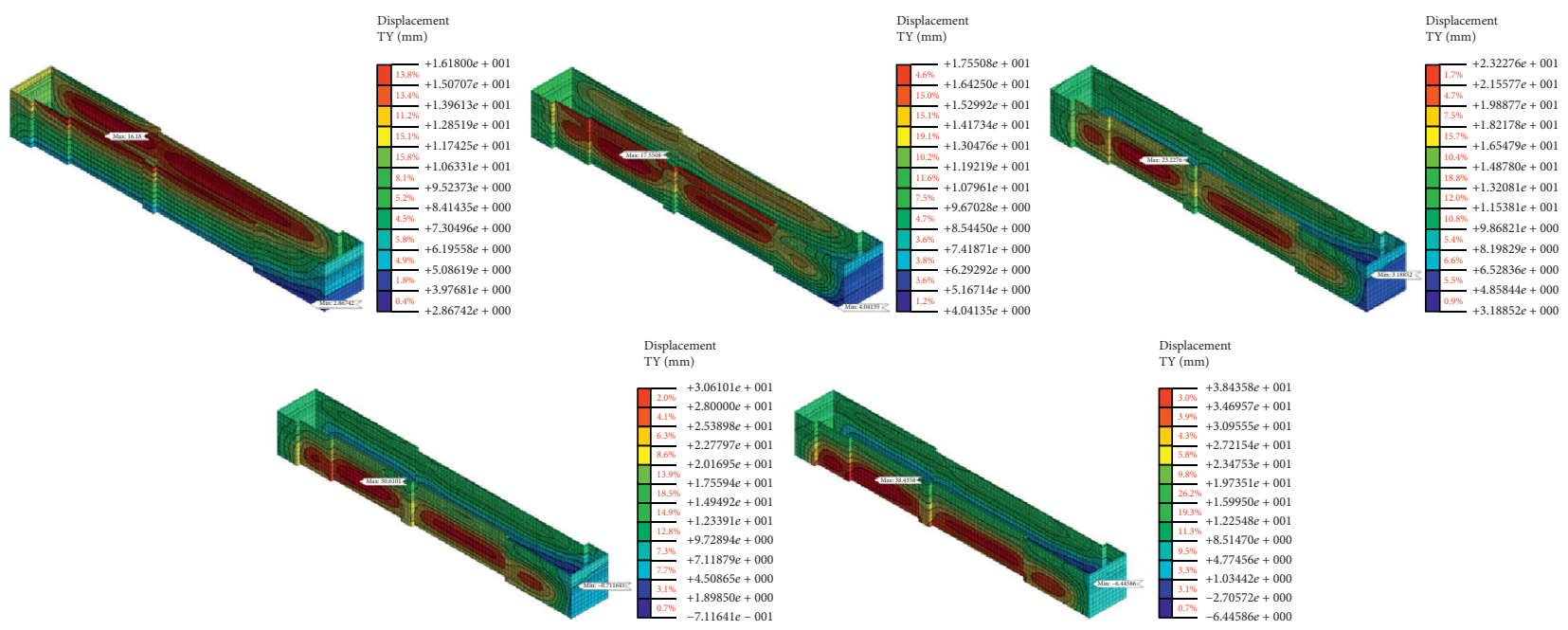

FIgURE 3: The horizontal displacement of the long side of the underground diaphragm wall in the $Y$-direction under each analysis condition.

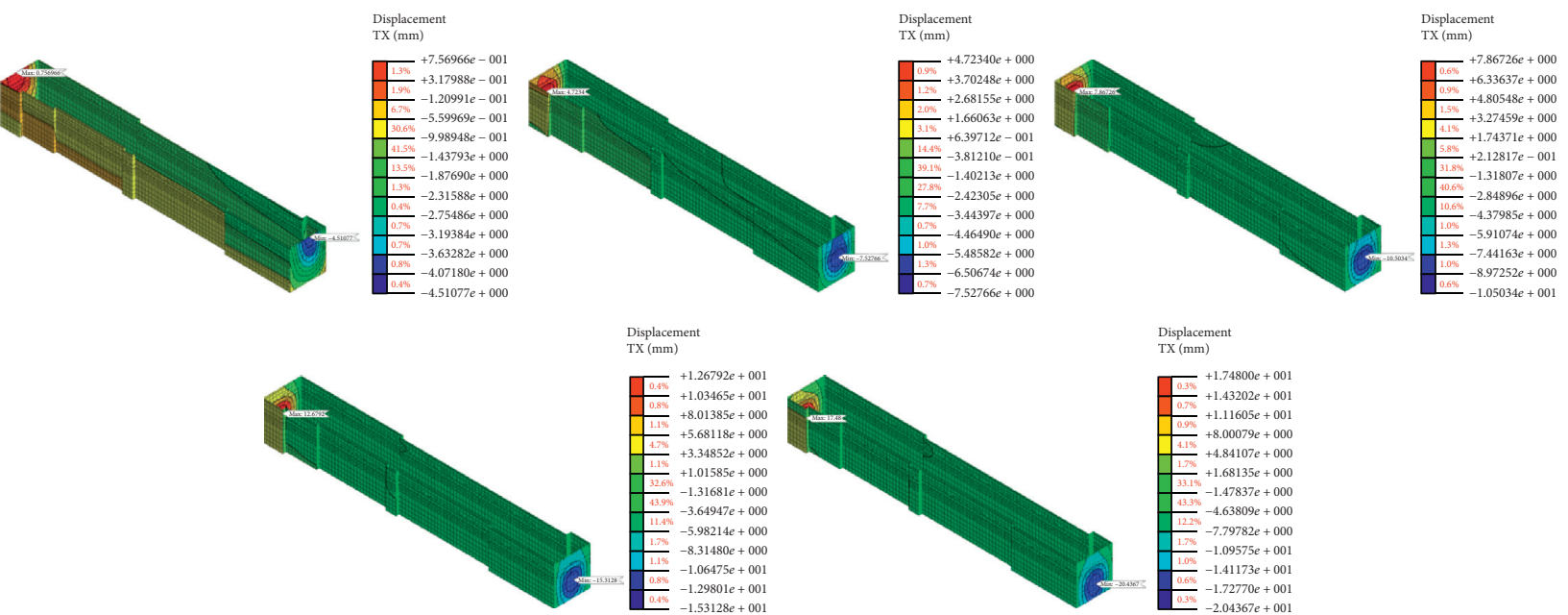

FIgURE 4: The horizontal displacement of the short side of the underground diaphragm wall in the $X$-direction under each analysis condition. 


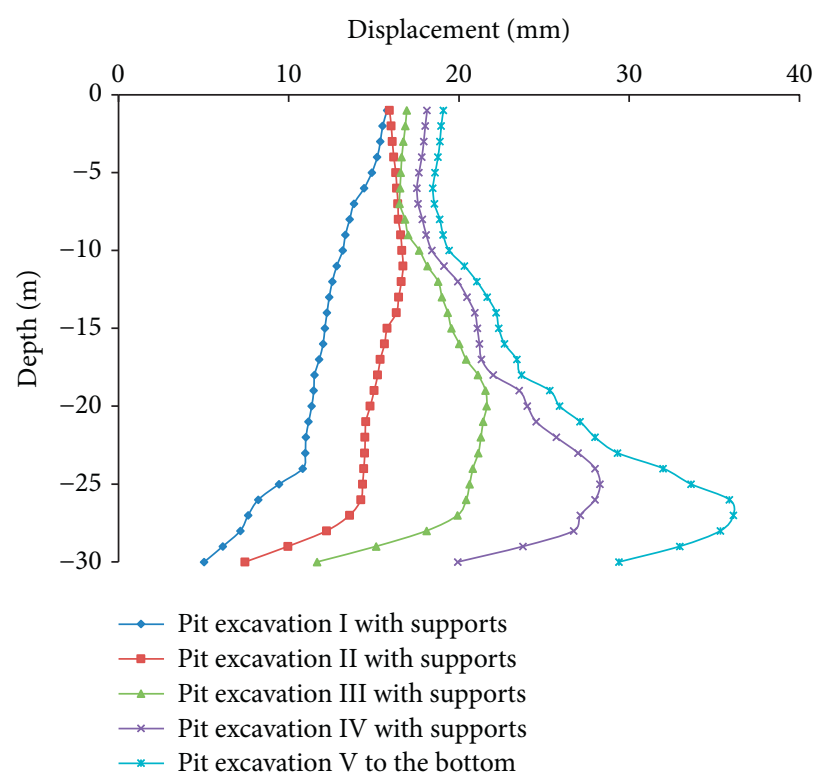

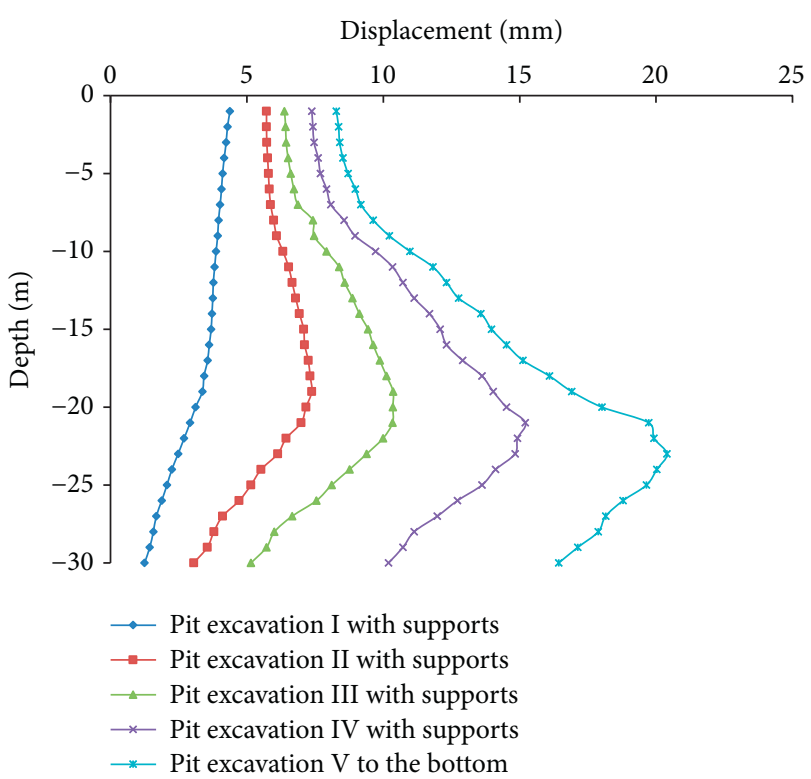

(b)

(a)

Displacement (mm)

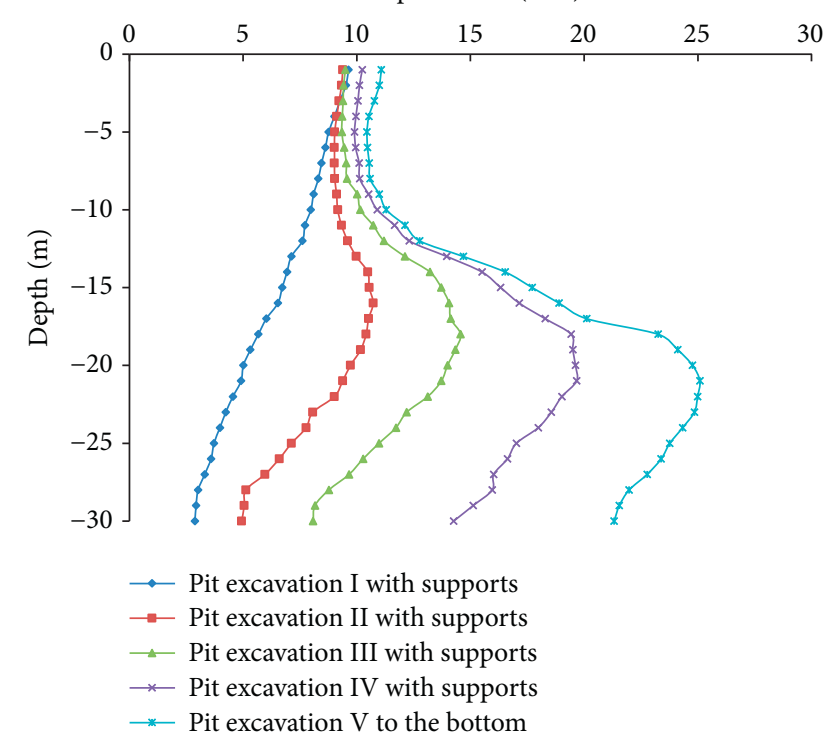

(c)

FigURE 5: Horizontal displacement simulation curve of the underground diaphragm wall. (a) Middle section of the long side on the east side of the foundation pit. (b) Middle section of the short side on the north side of the foundation pit. (c) East section of the north end of the foundation pit.

it is necessary to strengthen the monitoring of the axial force of the second support of the foundation pit, deal with the site stacking in time, and control the construction excavation progress.

4.3. Comparative Analysis of Numerical Simulation and Measured Values. Two different environments: numerical simulation and field practice are analyzed, in order to compare the general stress and deformation characteristics of deep foundation pit construction in the subway station. In the established three-dimensional numerical model in this paper, the horizontal displacement calculation value of the underground diaphragm wall at the standard section of the foundation pit where the diagonal hole ZQT6 is located, the calculation value of the axial force of the support in each track, and the calculation value of the ground surface settlement around the foundation pit are taken as references, and the analysis is carried out combining with the measured data of this section. According to the horizontal displacement cloud map of the underground diaphragm wall, the calculation results of the horizontal displacement of the underground 
TABLE 5: The axial force of the internal support under each analysis condition.

\begin{tabular}{|c|c|c|c|c|c|c|}
\hline Support & Location & Scenario 3 & Scenario 4 & Scenario 5 & Scenario 6 & Scenario 7 \\
\hline \multirow{3}{*}{ First track support } & Standard section horizontal bracing & -182.32 & -155.12 & -112.34 & -103.25 & -98.99 \\
\hline & North-end horizontal straight bracing & -112.33 & -72.19 & -69.12 & -62.56 & -60.12 \\
\hline & North-end horizontal diagonal bracing & -144.12 & -112.38 & -103.13 & -101.92 & -97.98 \\
\hline \multirow{3}{*}{ Second track support } & Standard section horizontal bracing & - & -1620.12 & -2512.34 & -2533.13 & -2413.22 \\
\hline & North-end horizontal straight bracing & - & -1123.32 & -2302.12 & -2213.45 & -2302.15 \\
\hline & North-end horizontal diagonal bracing & - & -1238.12 & -1772.33 & -1998.39 & -1897.12 \\
\hline \multirow{3}{*}{ Third track support } & Standard section horizontal bracing & - & - & -932.17 & -732.17 & -779.73 \\
\hline & North-end horizontal straight bracing & - & - & -715.34 & -613.45 & -628.76 \\
\hline & North-end horizontal diagonal bracing & - & - & -996.76 & -772.81 & -776.14 \\
\hline \multirow{3}{*}{ Fourth track support } & Standard section horizontal bracing & - & - & - & -573.11 & -771.43 \\
\hline & North-end horizontal straight bracing & - & - & - & -415.07 & -524.17 \\
\hline & North-end horizontal diagonal bracing & - & - & - & -608.18 & -812.12 \\
\hline
\end{tabular}

diaphragm wall when the foundation pit is excavated to the bottom of the pit are extracted, and the comparison between the deformation curves of the underground diaphragm wall obtained by combining the monitoring data is shown in Figure 6.

It can be seen from the figure that there are certain differences between the two, especially on the side far away from the existing station, but on the whole, the development trend of the horizontal displacement of the underground diaphragm wall reflected by the calculation results of the three-dimensional model is roughly the same as the actual situation. It is easy to observe that, at the top of the diaphragm wall, the calculation result of the three-dimensional model is greater than the measured value, indicating that, for similar long-strip foundation pits, in order to better control the deformation of the foundation pit, it is necessary to excavate the foundation pit in sections and layer by layer during the actual construction process. At the same time, it also proved that the foundation pit excavation construction plan adopted by this project is reasonable and feasible.

Table 6 shows the comparison between the calculated values of the model and the measured values of the internal supports in each road at each construction stage. It can be seen from Table 6 that when the first support is excavated and supported in the foundation pit, the calculated value of the model showed that the support was under compression, but in fact, the support received a tension of $72.12 \mathrm{kN}$; in the subsequent construction conditions, the actual measured values of the axial force of the first and third supports are greater than the simulated calculated values, and at the same time, the actual measured values of the axial forces of the second and fourth supports are less than the calculated values. The analysis of the above situation combined with the site construction log shows that, in the actual construction process, the support force is not only caused by the excavation and unloading of the soil in the foundation pit itself but also affected by the construction load and the dynamic changes of the construction conditions around the site. In the numerical simulation, one-time excavation of the large area layer by layer makes the foundation pit exhibit different stress and deformation characteristics from the envelop enclosure under the complex and changeable construction environment after the first excavation.

Figure 7 shows the surface settlement curve of the standard section taken away from the existing station when the three-dimensional model is excavated to the bottom of the foundation pit, Figure 8 shows the layout of some ground settlement measurement points on site, and Figure 9 shows the surface settlement changes at the same side of the standard section of the foundation pit at equal intervals. The measured data according to the time nodes are shown in Table 7. Combined with the data in the table, it can be found that the final ground settlement around the foundation pit calculated by the three-dimensional model is greater than the actual ground settlement. The analysis believes that this is also related to the fact that the simulation of the model construction conditions is different from the complex excavation and unloading methods of the foundation pit in the actual construction process. The maximum surface settlement appears at a distance of $13 \mathrm{~m}$ from the edge of the foundation pit, which is about $-10.3 \mathrm{~mm}$. The location is relatively close to the location of the measured maximum value, and the "groove" phenomenon of the final surface settlement curve in the three-dimensional model is very similar to the situation reflected by the corresponding measured data, indicating that the model can simulate the settlement changes of the surrounding ground surface during the construction of the foundation pit to a certain extent. 


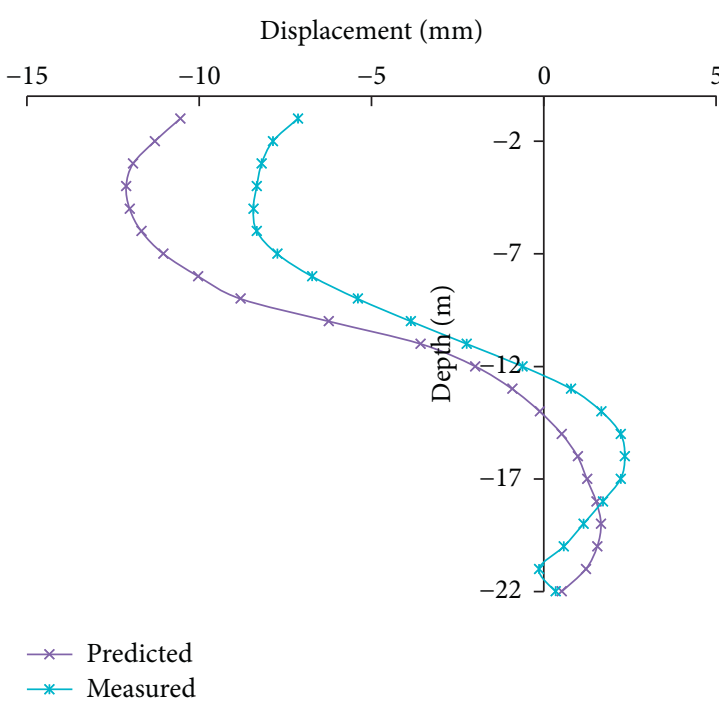

(a)

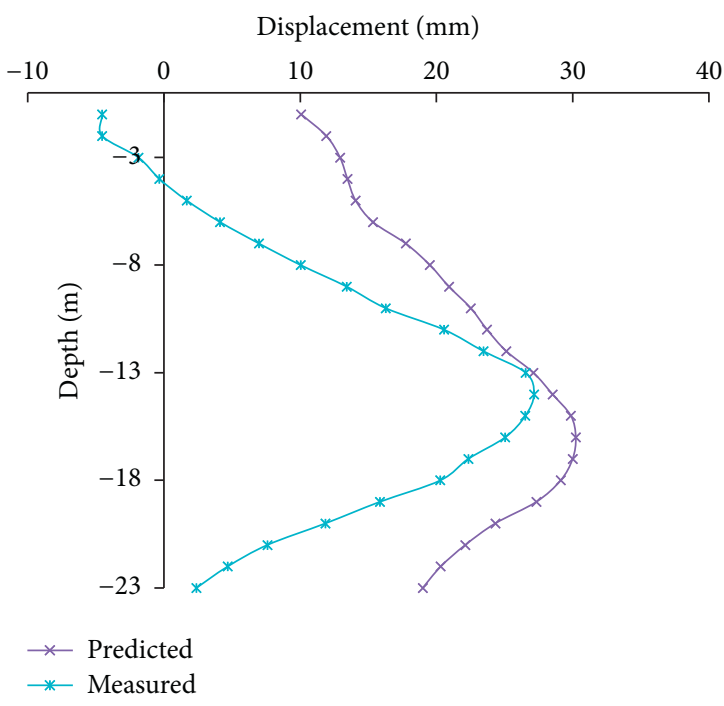

(b)

FIGURE 6: Comparison of the horizontal displacement of the underground diaphragm wall. (a) Horizontal displacement of the underground diaphragm wall adjacent to the existing station. (b) Horizontal displacement of the underground diaphragm wall away from the existing station.

TABLE 6: The axial force comparison of the internal support under each analysis condition.

\begin{tabular}{|c|c|c|c|c|c|c|}
\hline Support & Type & $\begin{array}{c}\text { The first time } \\
\text { excavation } \\
\text { support }\end{array}$ & $\begin{array}{l}\text { The second time } \\
\text { excavation support }\end{array}$ & $\begin{array}{l}\text { The third time } \\
\text { excavation support }\end{array}$ & $\begin{array}{l}\text { The fourth time } \\
\text { excavation support }\end{array}$ & $\begin{array}{l}\text { Excavation of the } \\
\text { foundation pit to the base }\end{array}$ \\
\hline \multirow{2}{*}{$\begin{array}{l}\text { First track } \\
\text { support }\end{array}$} & $\begin{array}{l}\text { Predicted } \\
\text { value }\end{array}$ & -173.13 & -133.45 & -101.96 & -92.36 & -89.73 \\
\hline & $\begin{array}{l}\text { Measured } \\
\text { value }\end{array}$ & 72.12 & -477.72 & -402.52 & -336.92 & -322.66 \\
\hline \multirow{2}{*}{$\begin{array}{l}\text { Second } \\
\text { track } \\
\text { support }\end{array}$} & $\begin{array}{l}\text { Predicted } \\
\text { value }\end{array}$ & - & -1024.42 & -1205.92 & -1313.35 & -1301.45 \\
\hline & $\begin{array}{l}\text { Measured } \\
\text { value }\end{array}$ & - & -633.45 & -887.93 & -992.36 & -1027.92 \\
\hline \multirow{2}{*}{$\begin{array}{l}\text { Third track } \\
\text { support }\end{array}$} & $\begin{array}{l}\text { Predicted } \\
\text { value }\end{array}$ & - & - & -875.24 & -793.55 & -823.66 \\
\hline & $\begin{array}{l}\text { Measured } \\
\text { value }\end{array}$ & - & - & -1025.72 & -1092.31 & -1242.34 \\
\hline \multirow{2}{*}{$\begin{array}{l}\text { Fourth } \\
\text { track } \\
\text { support }\end{array}$} & $\begin{array}{l}\text { Predicted } \\
\text { value }\end{array}$ & - & - & - & -433.25 & -544.27 \\
\hline & $\begin{array}{l}\text { Measured } \\
\text { value }\end{array}$ & - & - & - & -322.12 & -452.72 \\
\hline
\end{tabular}

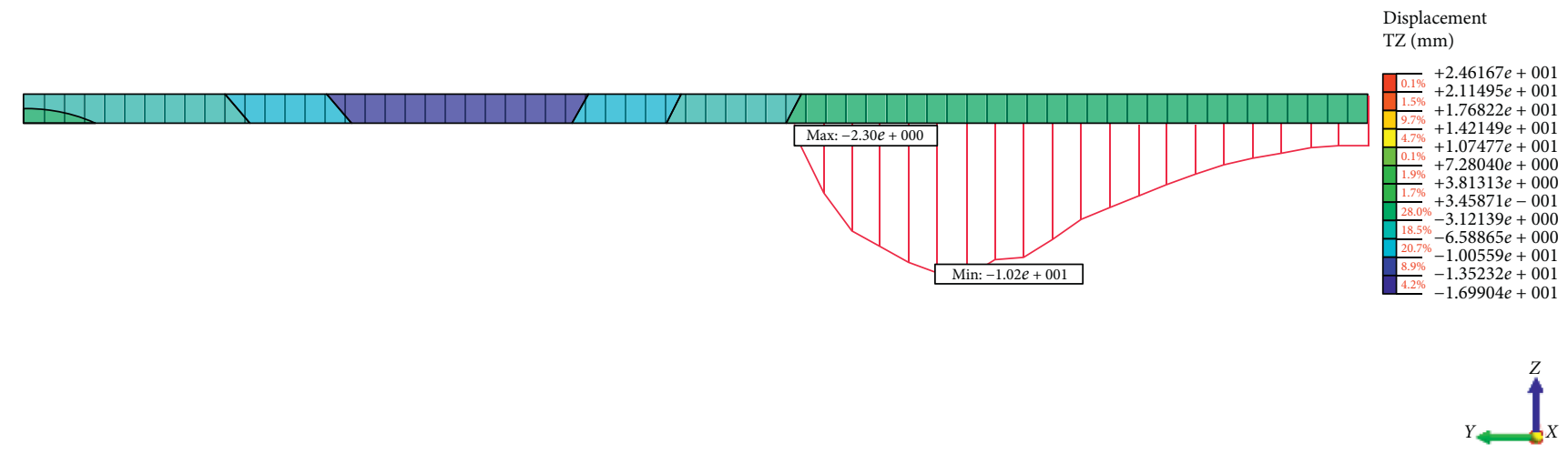

FiguRE 7: Settlement of the surrounding ground when the foundation pit is excavated to the bottom. (a) Horizontal displacement of the underground diaphragm wall adjacent to the existing station. (b) Horizontal displacement of the underground diaphragm wall away from the existing station. 


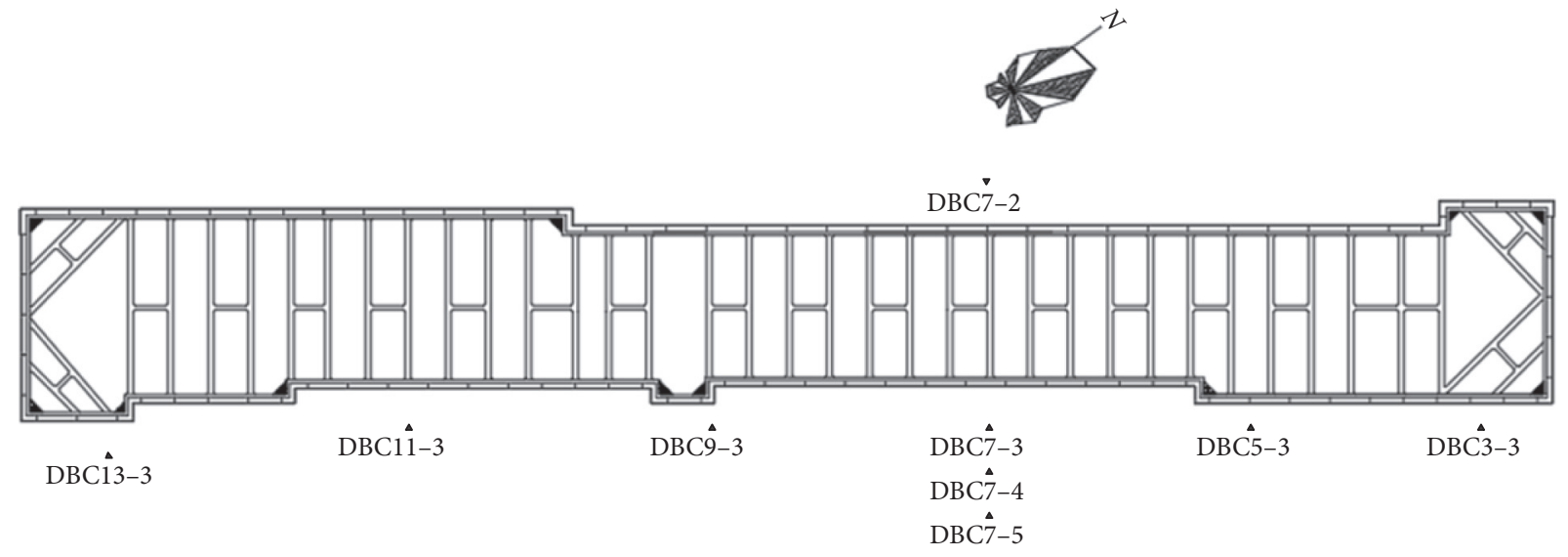

FIGURE 8: Layout of the surrounding ground subsidence measuring points.

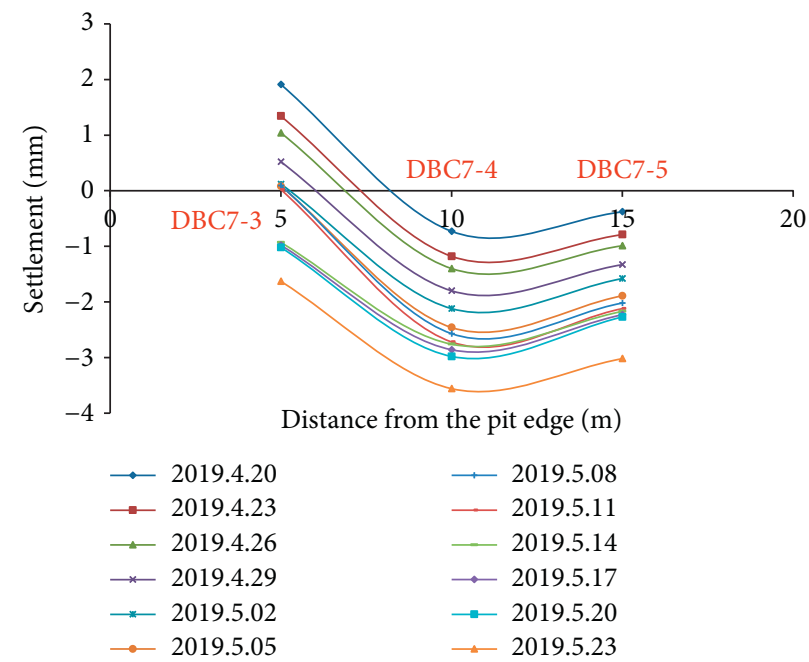

FIGURE 9: Surface settlement variation of equidistant distance.

TABLE 7: The ground surface settlement about DBC7-3 to DBC7-5.

\begin{tabular}{lccc}
\hline Time notes & DBC7-3 & DBC7-4 & DBC7-5 \\
\hline 2019.4 .20 & 1.91 & -0.73 & -0.38 \\
2019.4 .23 & 1.34 & -1.18 & -0.79 \\
2019.4 .26 & 1.04 & -1.4 & -0.99 \\
2019.4 .29 & 0.52 & -1.8 & -1.33 \\
2019.5 .02 & 0.12 & -2.12 & -1.58 \\
2019.5 .05 & 0.08 & -2.46 & -1.89 \\
2019.5 .08 & 0.09 & -2.57 & -2.02 \\
2019.5 .11 & 0.02 & -2.72 & -2.12 \\
2019.5 .14 & -0.93 & -2.76 & -2.17 \\
2019.5 .17 & -0.98 & -2.86 & -2.23 \\
2019.5 .20 & -1.02 & -2.98 & -2.27 \\
2019.5 .23 & -1.63 & -3.56 & -3.02 \\
\hline
\end{tabular}

\section{Conclusions}

Through the establishment of a three-dimensional finite element numerical analysis model to simulate the excavation and support construction process of the deep foundation pit of the newly built subway transfer station, the force and deformation characteristics of the deep foundation pit during the construction process under the condition of the adjacent existing subway station are studied, including the horizontal displacement of the underground diaphragm 
wall, the axial force of the internal support, and the surrounding ground settlement; at the same time, a comparative analysis is carried out based on the collation results of the corresponding actual measured data on site, and the conclusions are as follows:

(1) The deformation of the foundation pit during the excavation and construction process gradually develops into the foundation pit; the maximum horizontal displacement of the underground diaphragm wall on each side of the foundation pit is in the middle area of the side and gradually descends along the wall as the foundation pit continues to be excavated. It is stabilized at the depth of $2 / 3$ wall height below the top of the wall. The deformation of the diaphragm wall on the long side of the foundation pit is more obvious than that on the short side of the foundation pit. And the maximum deformation of the underground diaphragm wall on the long side of the foundation pit is close to twice the maximum deformation of the underground diaphragm wall on the short side.

(2) The underground diaphragm wall at the middle of the short side of the north side of the foundation pit has the smallest deformation, and the second is near the east side of the north end of the foundation pit. The deformation of the underground diaphragm wall at the middle of the long side of the foundation pit is the largest. This area should be used as a key area for monitoring the deformation of the retaining structure during the excavation and construction of the deep foundation pit.

(3) With the progress of construction conditions, the axial force of the first support at different positions on the plane of the foundation pit has decreased. The force of the first support at different positions of the foundation pit under various conditions is as follows: standard section horizontal bracing $>$ north-end horizontal diagonal bracing $>$ north-end horizontal straight bracing, reflecting the spatial effect at the end of the foundation pit. It is beneficial to the stress of the first support; it is beneficial to the force of the first support; and the axial forces of the second and third supports at each position of the foundation pit surface fluctuate up and down with the progress of the working conditions and eventually become stable. After the second and fourth supports are set up, the axial force of the previous support is reduced.

(4) During the entire excavation process of the foundation pit, the axial force of the second support is the largest, so the monitoring of the axial force of the second support of the foundation pit should be strengthened, the piled load on the site should be handled in time, and the construction progress should be controlled.

(5) The influence range of the surface settlement gradually expands to the surroundings as the construction conditions progress, and its settlement value continues to increase. The soil on the surface of the site in the open area on the east side of the foundation pit appears to be sinking under all analysis conditions, and when the foundation pit is excavated to the base, its settlement shows a groove phenomenon in the short side of the foundation pit.

(6) The comparison between numerical simulation analysis and actual measurement results shows that numerical simulation can better reflect the general mechanical characteristics of the foundation pit with the progress of the construction process to a certain extent. However, it is still limited because it cannot fully and real-time respond to the dynamic changes of the actual site construction environment. In the actual construction process, such foundation pits should be excavated layer by layer in a segmented and partitioned manner.

\section{Data Availability}

The measured data used to support the findings of this study are included within the article.

\section{Conflicts of Interest}

The authors declare that there are no conflicts of interest.

\section{References}

[1] J. Liu, H. Yao, and J. Ren, "Monitoring and numerical simulation of deformation of retaining structure in subway station foundation pit," Rock and Soil Mechanics, vol. 31, no. 2, pp. 456-461, 2010.

[2] Y. Liu, Z. Feng, G. Huang et al., "The study in predicting the deformation of supporting structure for deep foundation pit of Beijing railway," Chinese Journal of Underground Space and Engineering, vol. 5, no. 2, pp. 329-335, 2009.

[3] X. Xie, G.-B. Liu, Z. Li et al., "Analysis of soil layers displacement characteristics in foundation pit adjacent to subway station," Chinese Journal of Underground Space and Engineering, vol. 3, no. 4, pp. 742-757, 2007.

[4] Y. S. Chang and W. H. Yu, "Analysis on influence of deep pit construction on neighboring metro tunnel," Chinese Journal of Underground Space and Engineering, vol. 9, no. 2, pp. 352-358, 2013.

[5] M. S. Huang and W. D. Wang, "Responses of existing tunnels induced by adjacent excavation in soft soils," Rock and Soil Mechanics, vol. 30, no. 5, pp. 1373-1380, 2009.

[6] T. W. Lambe, "Braced excavations, lateral stresses in the ground and design of earth-retaining structures," Soil Mechanics and Foundations Division, vol. 96, 1970.

[7] G. B. Griggs, K. Patsch, and L. E. Savoy, Living with the Changing California Coast, University of California Press, Berkeley, CA, USA, 2005.

[8] A. B. Fourie and D. M. Potts, "The behavior of a propped retaining wall: results of a numerical experiment," GeoTechnique, vol. 34, no. 3, pp. 383-404, 1984.

[9] C. Yoo and D. Lee, "Deep excavation-induced ground surface movement characteristics-a numerical investigation," Computers and Geotechnics, vol. 35, no. 2, pp. 231-252, 2008. 
[10] J.-G. Liu and Y.-W. Zeng, "Application of FLAC3D to simulation of foundation excavation and support," Rock and Soil Mechanics, vol. 27, no. 3, pp. 505-508, 2006.

[11] M. Li, J. Chen, A. Xu et al., "Interactive behavior between the deep excavation and close operating railway," Chinese Journal of Underground Space and Engineering, vol. 11, no. 2, pp. 435-439, 2015.

[12] T.-H. Yang, Z.-Z. Liang, and H.-Y. Liu, "Numerical simulation on the progressive processes of the earth surface subsidence caused by the excavation of subway," Chinese Journal of Rock Mechanics and Engineering, vol. 22, no. 11, pp. 16211625, 2002.

[13] J. Wang, L. Hu, L. Wu, Y. Tang, Y. Zhu, and P. Yang, "Hydraulic barrier function of the underground continuous concrete wall in the pit of subway station and its optimization," Environmental Geology, vol. 57, no. 2, pp. 447-453, 2009.

[14] N. Q. Zhou, P. A. Vermeer, R. Q. Lou et al., "Numerical simulation of deep foundation pit dewatering and optimization of land subsidence controlling," Engineering Geology, vol. 116, no. 3-4, pp. 251-260, 2010.

[15] B. Yuan, L. Xiong, L. Zhai et al., "Transparent synthetic soil and its application in modeling of soil-structure interaction using optical system," Frontiers in Earth Science, vol. 7, p. 276, 2019.

[16] B. Yuan, M. Sun, L. Xiong, Q. Luo, S. P. Pradhan, and H. Li, "Investigation of 3D deformation of transparent soil around a laterally loaded pile based on a hydraulic gradient model test," Journal of Building Engineering, vol. 28, no. 3, Article ID 101024, 2020.

[17] B. X. Yuan, M. Sun, Y. X. Wang, L. H. Zhai, and Q. Z. Luo, "Full 3D displacement measuring system for 3D displacement field of soil around a laterally loaded pile in transparent soil," International Journal of Geomechanics, vol. 19, no. 5, Article ID 04019028, 2019. 